\title{
Research on Regional Technology — Economy - Ecology Coordination Evaluation System in China
}

\author{
Dan $\mathrm{Wu}^{1, *}$ \\ ${ }^{1}$ School of Economics and Management, North China University of Technology, Beijing 100144, China \\ *Corresponding author.Email:wu_daniel@163.com
}

\begin{abstract}
Taking the eastern, central, western and north-eastern regions of China as the research objects, this paper quantitatively screens the evaluation indicators of regional scientific and technological innovation, economic development and ecological environment construction in China with the principal component analysis method. At the same time, the principal component analysis method and the capacity coupling degree model are combined; a coordinated evaluation model for scientific and technological innovation and economic development is constructed; the level of regional scientific and technological innovation, economic development and ecological environment construction in China is measured and calculated; and the level of coordination of regional scientific and technological innovation and economic development with the construction of the ecological environment is dynamically evaluated.
\end{abstract}

Keywords: Region, Technological innovation, Economic development, Ecological environment construction, Coordinated evaluation, Index, Level.

\section{INTRODUCTION}

At the Fifth Plenary Session of the 18th CPC Central Committee, five development concepts of "innovation, coordination, green, opening and sharing" are put forward, providing important strategic support for solving the problems of national economic and social development and planting development advantages. According to the report of the 19th National Congress of the Communist Party of China, the idea of "implementing the new development concept and building a modern economic system" is put forward, emphasizing that efforts must be made to speed up the construction of an industrial system with the coordinated development of science and technology, real economy, modern finance and human resources. Therefore, enhancing the ability

*Fund: General Project of Beijing Municipal Natural Science Foundation - " Research on the Bidirectional Optimal Adaptation of Water Resources and Industrial Structure Under the Coordinated Development of Beijing-Tianjin-Hebei Region" (No.: 9202005); Talent Project of North China University of Technology - "Research on the evaluation system of resource energy consumption management performance and collaborative governance ability in Beijing-Tianjin-Hebei region from the perspective of scientific and technological innovation" (No. XN020035). of scientific and technological innovation is an inexhaustible driving force to promote China's regional economic development and ecological environment construction. China's regional works focus on leading the transformation and upgrading of the real economy by scientific and technological innovation, and promoting the coordinated development of scientific and technological innovation, economic development and ecological environment construction. Therefore, the coordination level of regional scientific and technological innovation, economic development and ecological environment construction in China is comprehensively evaluated.

Science and technology innovation index includes input index and output index. Science and technology financial input and science and technology human input are widely adopted as science and technology input index by scholars because of their easy quantification [1], [2], [3], [4], [5], [6]. Science and technology output index is divided into direct output index and indirect output index. Direct output index is mainly evaluated by papers and patents [7], [8], [9], and the indirect output index is evaluated by the marketization of scientific research achievements [10], [11]. The 
definition of economic development level based on the existing results is mainly studied from the aspects of economic scale, economic structure, consumption level, population structure, social welfare, etc. [12], [13], [14], [15]. Economic development indicators mainly include economic development level indicators, industrial structure indicators, national living standards indicators, education level indicators, employment indicators, and urbanization level indicators [16], [17], [18], [19], [20]. The definition of ecological environmental construction level based on the existing achievements is mainly studied from the aspects of resource constraint level, environmental pollution degree and environmental governance intensity [21], [22], [23]. Ecological environment construction indicators mainly include environmental pollution indicators, pollution control indicators and resource and energy stock indicators [24], [25], [26], [27], [28], [29], [30], [31]. Liu Jinsong used data envelopment analysis to evaluate the coordination degree between technological progress and economic growth in ethnic minority areas; [32], [33] Chen Xun et al. constructed the evaluation index system of scientific and technological progress and economic development level, and used comprehensive evaluation method to calculate the coordination degree of scientific and technological progress and economic development in Chongqing and Xinjiang, which provided theoretical basis for the coordinated development of science and technology and economy in the two areas; [34], [35] Guo Jiangjiang et al. analyzed the coordination degree of science and technology and economic development of 29 provinces and cities in China from the macro perspective of inter provincial differences. According to the research, there is always a positive interaction between science and technology and economic development in various regions. The coordinative degree evaluation based on Kuznets curve is mostly used to evaluate the coordinative development between economic and social development and ecological environment construction, that is, to judge the coordinative development state between economic development and ecological environment construction by testing whether the relationship between economic development and ecological environment construction meets the Kuznets curve hypothesis [36], [37], [38], [39], [40], [41]. According to the research, there is inverted U-shaped relationship between the ecological environment and economic development.

\section{RESEARCH METHOD DESIGN}

\subsection{Evaluation Index Design}

Based on the existing literature, science and technology input is mainly divided into science and technology human investment and science and technology financial investment, which are generally expressed by indicators such as R\&D personnel, R\&D expenditure, and high-tech industry input; science and technology output is mainly divided into direct science and technology output and indirect science and technology output, which are generally expressed by indicators such as papers, patents, technology market conditions, high-tech industry conditions, and new product conditions. Combining the importance of indicators and the availability of data, $R \& D$ personnel $\left(X_{1}\right)$, R\&D full-time personnel $\left(\mathrm{X}_{2}\right), \mathrm{R} \& \mathrm{D}$ personnel fulltime equivalent $\left(\mathrm{X}_{3}\right), \mathrm{R} \& \mathrm{D}$ personnel of high-tech industry $\left(\mathrm{X}_{4}\right), \mathrm{R} \& \mathrm{D}$ full-time personnel of hightech industry $\left(\mathrm{X}_{5}\right), \mathrm{R} \& \mathrm{D}$ researchers of high-tech industry $\left(\mathrm{X}_{6}\right)$, and $\mathrm{R} \& \mathrm{D}$ personnel equivalent to full-time equivalent of high-tech industry $\left(\mathrm{X}_{7}\right)$ are selected as indicators of scientific and technological human input; R\&D internal expenditure $\left(\mathrm{X}_{8}\right), \mathrm{R} \& \mathrm{D}$ expenditure intensity $\left(\mathrm{X}_{9}\right), \quad \mathrm{R} \& \mathrm{D}$ internal expenditure of high-tech industry $\left(\mathrm{X}_{10}\right), \mathrm{R} \& \mathrm{D}$ external expenditure of high-tech industry $\left(\mathrm{X}_{11}\right)$, new product development expenditure of high-tech industry $\left(\mathrm{X}_{12}\right)$ are selected as indicators of scientific and technological financial investment; the number of patent applications granted $\left(\mathrm{Y}_{1}\right)$ and the number of patent applications accepted $\left(\mathrm{Y}_{2}\right)$ are selected as the direct output indicator of science and technology; the sales revenue of new products in the high-tech industry $\left(\mathrm{Y}_{3}\right)$, the export of new products in the high-tech industry $\left(\mathrm{Y}_{4}\right)$, the contract amount of the technology input region $\left(\mathrm{Y}_{5}\right)$, and the contract amount of the technology output region $\left(\mathrm{Y}_{6}\right)$ are selected as the indirect output indicators of science and technology.

According to the existing literature, economic development indicators include economic level indicators, consumption level indicators, population indicators, urbanization indicators, employment indicators, education level indicators, etc. Combining the importance of indicators and the availability of data, regional GDP $\left(\mathrm{Z}_{1}\right)$, secondary industry added value $\left(Z_{2}\right)$, tertiary industry added value $\left(Z_{3}\right)$, local fiscal general budget revenue $\left(Z_{4}\right)$, the fixed asset investment of whole society $\left(Z_{5}\right)$ and industrial added value $\left(\mathrm{Z}_{6}\right)$ are selected as economic level indicators; total retail sales of consumer goods 
$\left(\mathrm{Z}_{7}\right)$ and household consumption level $\left(\mathrm{Z}_{8}\right)$ are used as social consumption level indicators; permanent residents at the end of the year are used as population indicators $\left(Z_{9}\right)$; urban population $\left(Z_{10}\right)$ is used as an indicator of urbanization; the number of registered unemployed persons in cities and towns $\left(Z_{11}\right)$ is used as an indicator of employment status, and local financial education expenditure $\left(Z_{12}\right)$ is used as an indicator of education level.

According to the existing literature, the ecological environment construction indicators mainly include environmental constraint indicators, environmental protection indicators, and environmental pollution indicators. Combining the importance of indicators and the availability of data, total water consumption $\left(\mathrm{A}_{1}\right)$, forestry land area $\left(A_{2}\right)$, forest area $\left(A_{3}\right)$, forest stock volume $\left(A_{4}\right)$ are selected as environmental constraint indicators; industrial pollution control completed investment $\left(\mathrm{A}_{5}\right)$, local financial environmental protection expenditure $\left(\mathrm{A}_{6}\right)$ are used as environmental protection indicators; sulfur dioxide emissions $\left(\mathrm{A}_{7}\right)$, ammonia nitrogen emissions $\left(A_{8}\right)$, total wastewater emissions $\left(\mathrm{A}_{9}\right)$, chemical oxygen demand emissions $\left(\mathrm{A}_{10}\right)$, and the volume of domestic waste removal $\left(\mathrm{A}_{11}\right)$ are used as environmental pollution indicators.

The principle of selecting indicators based on representativeness is to perform principal component analysis on the initial indicators, and the indicators that have a greater contribution to the principal component factors can be screened out. The basic idea is as follows. It is supposed that the principal component factors are extracted from $n$ initial indicators. The initial indicator population is $X=\left(X_{1}, X_{2}, \cdots, X_{\mathrm{n}}\right)^{T}$, the extracted principal component factors population is $Y=\left(Y_{1}, Y_{2}, \cdots, Y_{m}\right)^{T}(m \leq n)$, and the column rank of $Y=\left(Y_{1}, Y_{2}, \cdots, Y_{m}\right)^{T}=m$. For $\left.Y_{i}=\alpha_{i}^{T} X_{(i=1,2, \cdots, m}\right), \alpha_{i}$ is the dimensional vector of $n \times 1, Y_{1}$ is the largest equation in the linear combination $\left(X_{1}, X_{2}, \cdots, X_{\mathrm{n}}\right)^{T} ; Y_{2}$ is the largest equation in all linear combinations $\left(X_{1}, X_{2}, \cdots, X_{\mathrm{n}}\right)^{T}$ that are not related with $Y_{1}$; by parity of reasoning, $Y_{m}$ is the largest equation in all linear combinations $\left(X_{1}, X_{2}, \cdots, X_{\mathrm{n}}\right)^{T}$ that are not related with $Y_{1}, Y_{2} \ldots Y_{m-1}$. Among them, the size of the variance represents the size of the principal component factor that can explain the amount of initial indicator information, so $Y_{i}$ is called $i$ principal component factor of $X$. The principal component factors reflect the index information of the main projection direction, and there is the problem of missing local information. On the basis of the selected index based on the representativeness, the important index which deviates from the main projection direction is added. Finally, the final index system of science and technology - economy - ecology coordination evaluation is determined (see "Figure $1 ")$. 


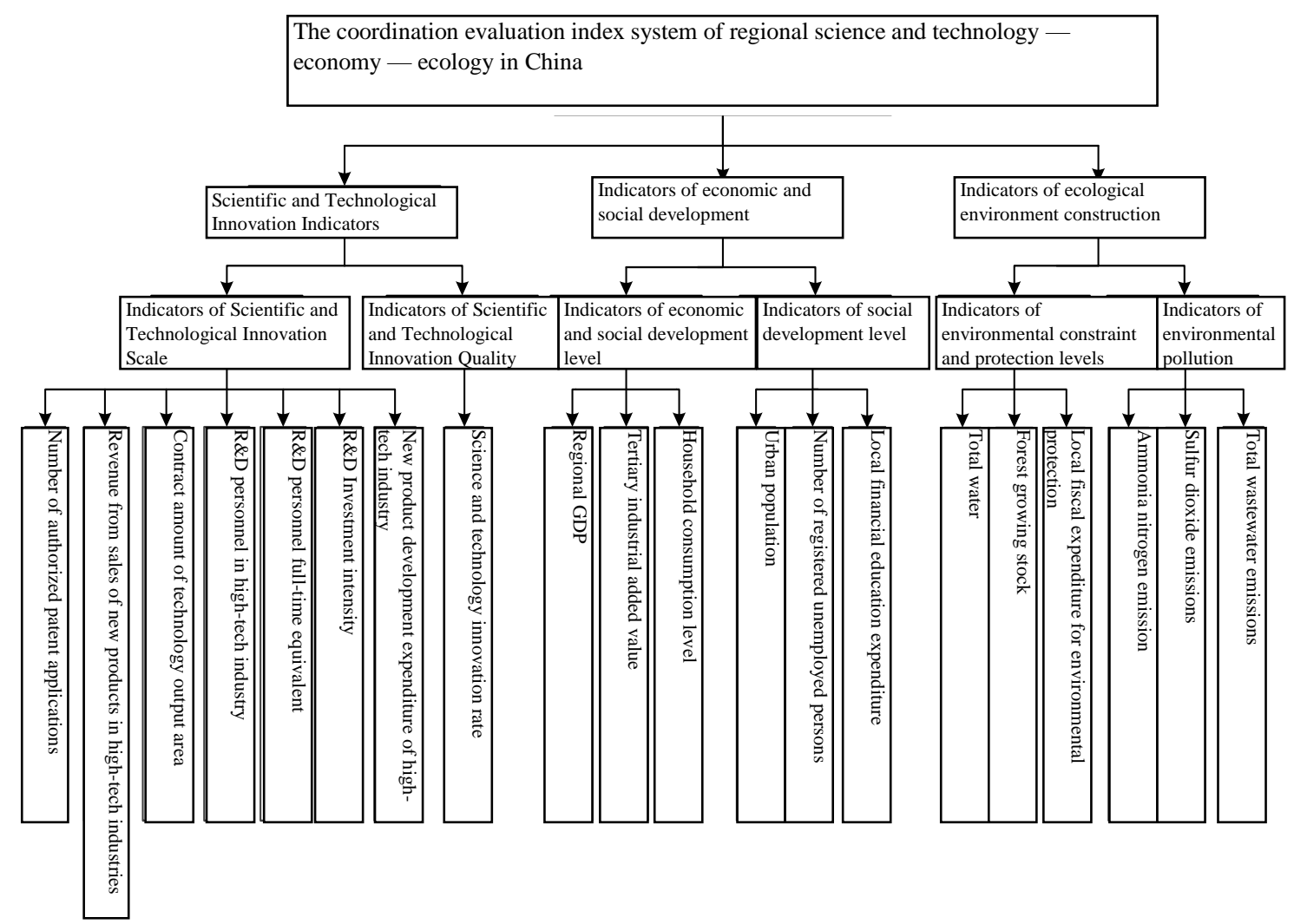

Figure 1 The coordination evaluation index system of regional science and technology — economy — ecology in China.

\subsection{Evaluation Model Construction}

Using principal component analysis method and capacity coupling degree model, this paper calculates the coordination degree and coordinated development degree of regional science and technology - economy - ecology.

Step 1: to standardize the evaluation index, which can be expressed as follows:

$$
q_{i}= \begin{cases}\frac{a_{i}}{\max \left\{a_{i}\right\}}, \begin{array}{l}
\text { Ai is an indicator that contributes } \\
\text { positively to the system }
\end{array} \\
\frac{\min \left\{a_{i}\right\}}{a_{i}}, \begin{array}{l}
\text { Ai is an indicator that contributes } \\
\text { negatively to the system }
\end{array}\end{cases}
$$

Step 2: to use principal component analysis method to determine the initial comprehensive level index of science and technology, economy and ecology. Based on the factor analysis of science and technology, economy and ecology index data, the principal component factor ${ }^{Q_{j}=\sum_{i=1}^{n} \beta_{i} q_{i}}$ is extracted, in which $\beta_{i}$ is the contribution rate of $i$ index factor $q_{i}$ to principal component factor ${ }^{Q_{j}}$. According to the variance contribution rate of each principal component factor, the initial comprehensive level index $L_{K}(t)=\sum_{j=1}^{m} \sigma_{j} Q_{j}$ of science and technology, economy and ecology at the moment $t$ is constructed. Among them, $\sigma_{j}$ is the variance contribution rate of $j$ principal component factor $Q_{j}$. The larger the comprehensive level index is, the higher the development level is.

Step 3: to determine the final comprehensive level index of science and technology, economy and ecology through adjustment. Since the principal component factors obey the standard normal distribution, the comprehensive level index determined by the principal component factors contains negative values. In order to ensure the calculation rationality and accuracy of the coordination degree, the coordinate transformation is carried out on initial comprehensive level index of science and technology, economy and ecology. Taking the maximum value of science and technology, economy and ecology as divisor respectively, the initial comprehensive level index is adjusted by normalization. $R_{k}(t)=\frac{L_{K}(t)+H}{\max \left\{L_{t}+H\right\}}, H$ 
is a constant. The positive comprehensive level index is obtained by taking the unit with the highest level of development in economy and ecology as the ruler.

Step 4, according to the capacity coupling degree model, the coordination degree and coordinated development degree of science and technology - economy - ecology is calculated. The formula is as follows.

$$
\left\{\begin{array}{l}
P=\frac{1}{K} \sum_{k=1}^{K} R_{k}(t) \\
C=\left[\frac{\prod_{k=1}^{K} R_{k}(t)}{P^{K}}\right]^{\frac{1}{K}} \\
D=\sqrt{C \times P}
\end{array}\right.
$$

In formula (2), $C$ refers to the coordination degree among science and technology, economy and ecology; $D$ refers to the coordinated development degree of science and technology, economy and ecology; $R_{k}(t)$ refers to the comprehensive development level of economy and ecology at $t ; P$ refers to the comprehensive development level of economy and economic ecology. It is to make the division of the coordination value and determine the value and significance of $C$ and $D$ (see "Table 1").

Table 1. The coordination classification of regional science and technology - economy — ecology

\begin{tabular}{llll} 
& interval & \multicolumn{1}{c}{$\mathrm{C}$} & $\mathrm{D}$ \\
\hline$\left[\begin{array}{ll}0.0, & 0.2\end{array}\right)$ & Extreme incoordination & extremely uncoordinated development \\
\hline$\left[\begin{array}{ll}0.2, & 0.6\end{array}\right)$ & incoordination & Uncoordinated development \\
\hline$\left[\begin{array}{ll}0.6, & 0.7\end{array}\right)$ & $\begin{array}{l}\text { Elementary } \\
\text { coordination }\end{array}$ & Elementary coordinated development \\
\hline$\left[\begin{array}{ll}0.7, & 0.8\end{array}\right)$ & medium coordination & medium coordinated development \\
\hline$\left[\begin{array}{ll}0.8, & 0.9\end{array}\right)$ & benign coordination & benign coordinated development \\
\hline$\left[\begin{array}{ll}0.9, & 1.0\end{array}\right)$ & $\begin{array}{l}\text { high-quality } \\
\text { coordination }\end{array}$ & high-quality coordinated development \\
\hline 1.0 & perfect coordination & perfect coordinated development
\end{tabular}

3. EVALUATION ON THE DEVELOPMENT LEVEL OF REGIONAL SCIENCE AND TECHNOLOGY - ECONOMY ECOLOGY IN CHINA

\subsection{Scientific and Technological Innovation Level}

This paper makes KMO and Bartlett test on four input indicators, three output indicators and scientific and technological innovation efficiency in eastern region, central region, western region and northeast region from 2009 to 2016. Taking one year as lag period, this paper selects the data of science and technology input indicators in eastern region, central region, western region and northeast region from 2009 to 2015 and the data of scientific and technological output index in eastern region, central region, western region and northeast region in China from 2010 to 2016. The final comprehensive index of scientific and technological innovation level is obtained by principal component analysis (see "Figure 2"). 


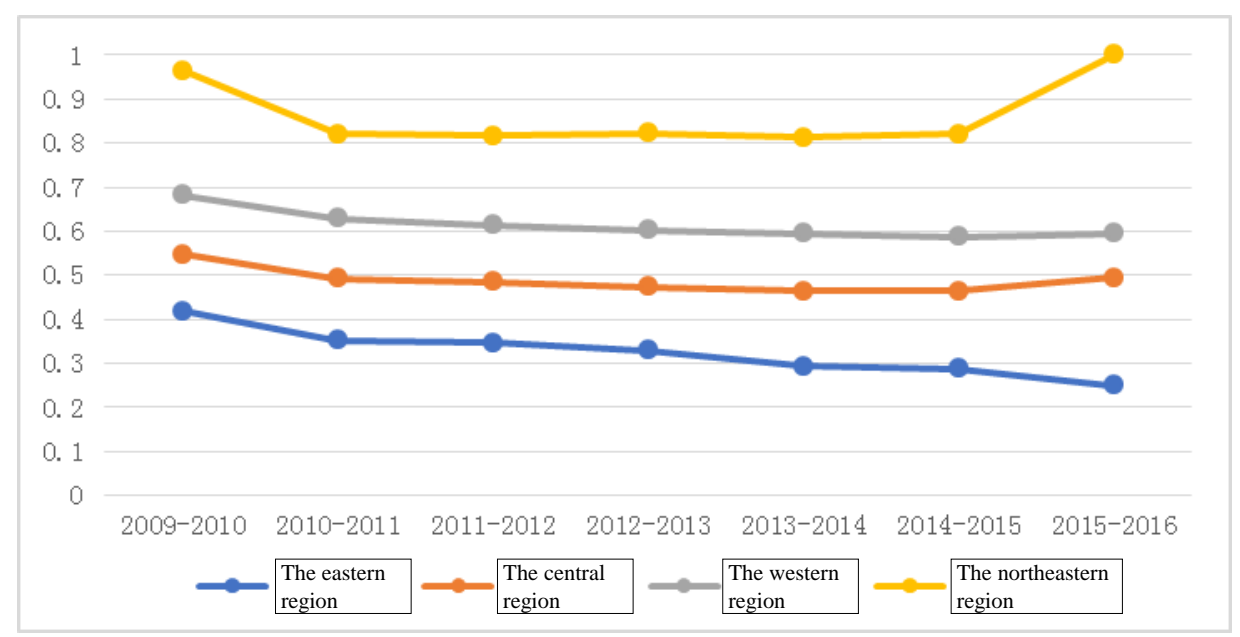

Figure 2 The comprehensive index of China's regional scientific and technological innovation level.

As can be seen from "Figure 2", the overall level of scientific and technological innovation in the eastern region, the central region, the western region and the northeast region is increasing year by year, and it decreases from the eastern, central, western and northeastern regions. There is a large gap between the level of technological innovation in the eastern region and the central, western, and northeastern regions. The comprehensive index of technological innovation level is about twice that of the central, western, and northeastern regions, and the gap is increasing year by year. The gap between the western region and the northeastern region is relatively small, and the comprehensive index of technological innovation level differs by 1 to 10 percentage points. In terms of growth rate, the eastern region has the largest growth rate from 2010 to 2016 , up to $50 \%$, followed by the central region $(13 \%)$, the western region $(11.9 \%)$, and the Northeast region $(5.6 \%)$. In terms of growth speed, the growth speed of the comprehensive index of scientific and technological innovation level in the eastern, central, western and northeastern regions fluctuated up and down over the six years. Among them, there was a general slowdown in the growth rate from 2012 to 2014, and even a decline in the index, which was generally achieved in 2013-2016. Compared with other years, the growth rate was higher.

\subsection{Economic Development Level}

After standardizing 6 indicators of economic development in the eastern, central, western and northeastern regions from 2009 to 2016, the KMO and Bartlett tests were carried out. Taking into account the lagging effect of local financial education expenditure on the education level, the one-year lag period principle is used according to the analysis of the level of science and technology. This indicator uses data from 2009-2015, and other indicators use data from 2010-2016. Principal component analysis method is used to obtain the final comprehensive index of economic and social development level (see "Figure 3"). 


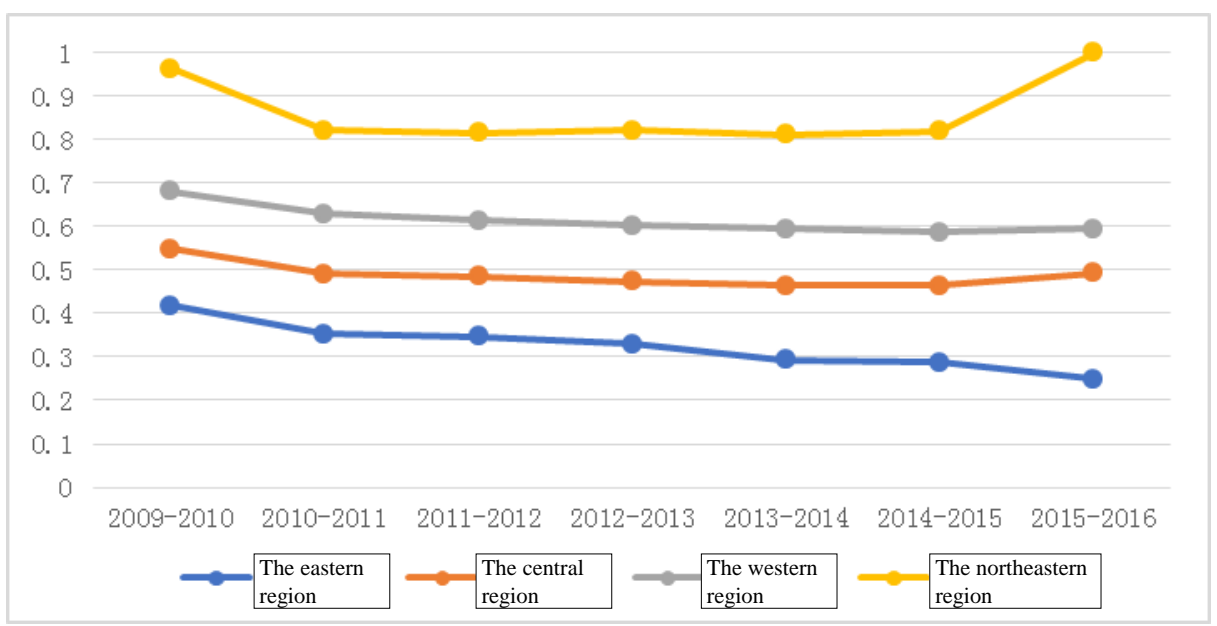

Figure 3 Comprehensive index of China's regional economic development level.

According to "Figure 3", the overall economic development level of the eastern, central, western and northeastern regions is increasing year by year, and is decreasing from the eastern, central, western to northeastern regions. In terms of the gap, the economic and social development level of the four major regions can be divided into three levels: the eastern region, the central and western region, and the northeastern region. The comprehensive index of the economic and social development level of the eastern region is 1.7-1.8 times that of the central and western region, and the comprehensive index of the economic and social development level of the central and western regions is about twice that of the northeast region. In terms of growth rate, from 2009 to 2016, the comprehensive index of economic and social development in the eastern region increased the most $(29.63 \%)$, followed by the western region $(17.25 \%)$ and the central region $(14.82 \%))$, northeast China $(5.89 \%)$. In terms of growth speed, the eastern, central, and western regions basically maintained growth rates of about 6.3 , 3.2, and 3.6 percentage points during 20092012, with the largest increase during 2011-2013. They were 7.07 percentage points, 4.39 percentage points, and 4.49 percentage points, respectively. The growth rate slowed down from 2012 to 2016, achieving growth rates of 4.9 percentage points, 1.9 percentage points, and 2.6 percentage points. The comprehensive index growth rate of economic and social development of Northeast China from 2009 to 2016 is slow and fluctuates greatly, and the average growth rate is quite different from that of the eastern, central, and western regions.

\subsection{Ecological Environment Construction Level}

The KMO and Bartlett tests were carried out after standardization of the 6 indicators for the construction of the ecological environment in the eastern, central, western and northeastern regions from 2009 to 2016. Taking into account the lag in the environmental impact of local fiscal environmental protection expenditures, one year was taken as the lag period. This indicator uses the data from 2009 to 2015, and other indicators use the data from 2010 to 2016. Principal component analysis method is used to obtain the final comprehensive index of ecological environment construction level (see "Figure 4"). 


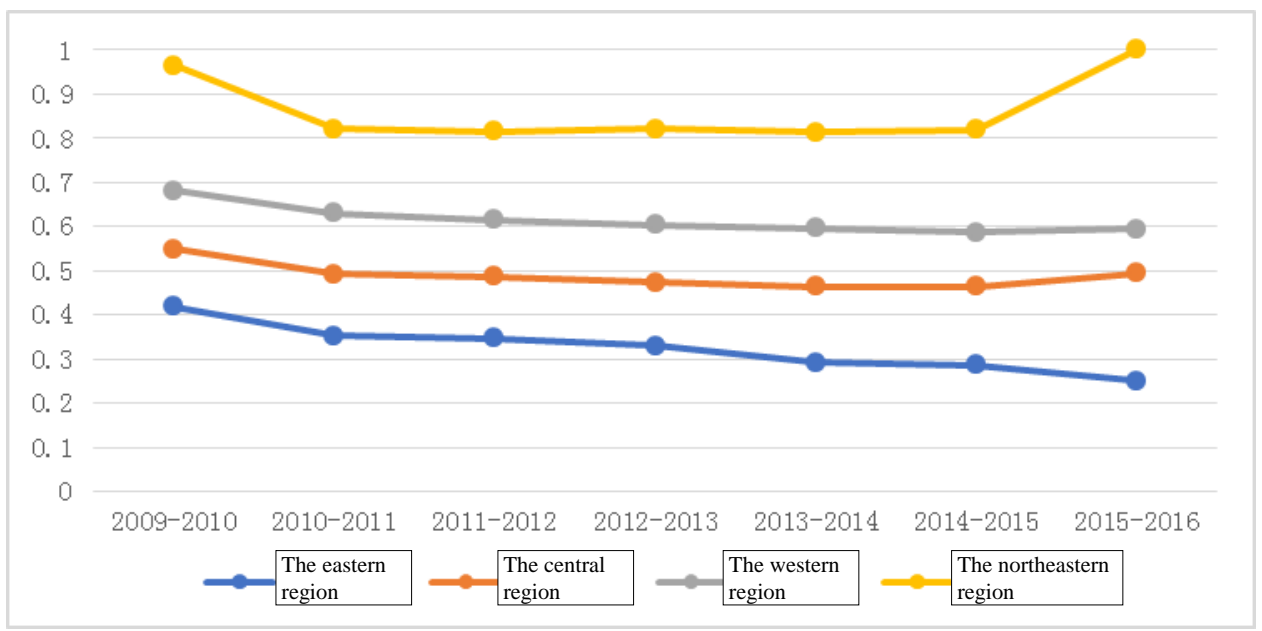

Figure 4 The comprehensive index of regional ecological environment construction level in China.

It can be seen from "Figure 4" that the ecological environment construction level of the eastern region, the central region, the western region and the northeast region increases. Among them, the ecological environment construction level of the eastern region, the central region and the western region shows a decreasing trend year by year as a whole. The ecological environment construction level of the northeast region reaches the highest level of more than 0.95 in the six years in addition to 2009-2010 and 2015-2016. The ecological environment construction level index has been maintained at about 0.8 . In terms of the gap, the gap between the northeast and the eastern region is relatively large, with an average difference of 54 percentage points, while the gap between the western region and the central region, and the gap between the central region and the eastern region is similar, with 12.65 percentage points and 16.36 percentage points respectively. In terms of the decline, compared with that of 20092010 , the decreasing amplitude is significant in the four major regions from 2010 to $2011,6.55,5.66$, 5.26 and 14.27 percentage points respectively. Compared with that of 2013-2014, the decline in 2014-2015 was less than that in other years, and the decline of the northeast region was the least in the rest years, within 0.6 percentage points. Compared with that in 2011-2013, 2013-2014, 2014-2015, there was an increase in 2012-2013, 2014-2015, 2015-2016. The central region and the western region showed the smallest decrease, within a decrease of 1 percentage point. The eastern region showed the largest decrease, with 16.85 percentage points in six years. The ecological environment construction in the eastern region, central region, western region and northeast region has not achieved continuous improvement, but the deterioration rate has slowed down.

\section{COORDINATION EVALUATION OF REGIONAL SCIENCE AND TECHNOLOGY - ECONOMY - ECOLOGY IN CHINA}

Using the capacity coupling degree model, the coordination degree and coordinated development degree of science and technology, economy and ecology in eastern region, central region, western region and northeast region from 2009 to 2016 are calculated (see "Table 2"). 
Table 2. The coordination degree and coordinated development degree of regional science and technology economy - ecology system in China

\begin{tabular}{rcccccccccc}
\hline & \multicolumn{2}{r}{ Year } & Eastern Region & \multicolumn{2}{c}{ the central region } & \multicolumn{2}{c}{ the west area } & \multicolumn{2}{c}{ the northeast } \\
& C & D & C & D & C & D & C & D \\
\hline $2009-2010$ & 0.9842 & 0.7151 & 0.7977 & 0.5241 & 0.7562 & 0.5308 & 0.5481 & 0.4657 \\
$2010-2011$ & 0.9597 & 0.7281 & 0.8845 & 0.5579 & 0.7907 & 0.5405 & 0.6876 & 0.5035 \\
$2011-2012$ & 0.9383 & 0.7684 & 0.8854 & 0.5661 & 0.8136 & 0.5565 & 0.6412 & 0.4806 \\
$2012-2013$ & 0.9185 & 0.7830 & 0.9028 & 0.5849 & 0.8463 & 0.5810 & 0.6654 & 0.4964 \\
$2013-2014$ & 0.8983 & 0.7684 & 0.9050 & 0.5888 & 0.8623 & 0.5952 & 0.6477 & 0.4861 \\
$2014-2015$ & 0.8792 & 0.7908 & 0.9369 & 0.6164 & 0.8881 & 0.6139 & 0.6762 & 0.5038 \\
$2015-2016$ & 0.8396 & 0.7934 & 0.9315 & 0.6308 & 0.9126 & 0.6418 & 0.6693 & 0.5464 \\
\hline
\end{tabular}

According to "Table 2", in terms of coordination, the average coordination degree of scientific and technological innovation, economic development and ecological environment construction in the eastern region, central region, western region and northeast region from 2009 to 2016 is 0.8824 , which is in a good coordination level as a whole. Among them, the eastern region has the best coordination of scientific and technological innovation, economic development and ecological environment construction, with an average coordination degree of 0.9168 , reaching the high-quality coordination level. However, from the perspective of time series, the coordination degree of scientific and technological innovation, economic development and ecological environment construction in the eastern region shows a downward trend, from the high-quality coordination level in 2009-2013 to the good coordination level in 2013-2016. The second is the central and western region. The average coordination degree of scientific and technological innovation, economic development and ecological environment construction is 0.8920 and 0.8385 respectively, reaching a good coordination level. From the time series, the coordination degree of scientific and technological innovation, economic development and ecological environment construction in the central region and the western region has basically increased year by year. The central region has increased from a moderate level of coordination in 2009-2010 to a good level of coordination in 2010-2010 and then to high-quality coordination of scientific and technological innovation, economic development and ecological environment construction in 2012-2016. The western region has increased from medium level of coordination in 2009-2011 to good level of coordination in 2011-2015, and then to high-quality coordination in 2015-2016. The worst coordination of scientific and technological innovation, economic development and ecological environment construction is in the northeast region, and the average coordination degree is 0.6479 , which is in the primary coordination level. However, the scientific and technological innovation, economic development and ecological environment construction in 2009-2010 are in an uncoordinated state, and the primary coordination has been realized since 2010. From the time series, the coordination degree of scientific and technological innovation, economic development and ecological environment construction has been in a fluctuating state.

From the perspective of coordinated development degree, the average coordinated development degree of scientific and technological innovation, economic development and ecological environment construction in eastern region, central region, western region and northeast region from 2009 to 2016 is 0.6417 , which is at the primary coordinated development level. Among them, the coordinated development of scientific and technological innovation, economic development and ecological environment construction in the eastern region is the best. The average coordinated development degree of scientific and technological innovation, economic development and ecological environment construction is 0.7639 , showing an increasing trend in the whole seven years. The coordinated development degree of scientific and technological innovation, economic development and ecological environment construction in each year is between 0.7 and 0.8 , that is, the development and ecological environment construction have always been at the medium coordinated development level, followed by the central region and the western region, and the average coordinated development degrees of 
scientific and technological innovation, economic development and ecological environment construction are 0.5813 and 0.5800 respectively, which are at the uncoordinated development level as a whole. However, in the seven years, the coordinated development degree of scientific and technological innovation, economic development and ecological environment construction in the central and western regions all increased year by year, from the uncoordinated development level in 2009-2014 to the primary coordinated development level in 2014-2015. The lowest level of coordinated development of scientific and technological innovation, economic development and ecological environment construction is in northeast China. The average value of coordinated development of scientific and technological innovation, economic development and ecological environment construction is 0.4975 , and the overall level of coordinated development is at the level of uncoordinated development. Moreover, the coordinated development of science and technology innovation, economic development and ecological environment construction in each year fluctuates, and all of them are at the level of uncoordinated development.

\section{CONCLUSION}

By comparing the degree of coordination and coordinated development of technological innovation, economic development and ecological environment construction in the eastern, central, western, and northeastern regions of China, it can be found that the gap of the coordination degree of scientific and technological innovation, economic development and ecological environment construction between the eastern region and the central region, the western region and the northeast region is higher than that of the coordinated development degree. The coordination degree of scientific and technological innovation, economic development and ecological environment construction is very high in the eastern region, the central region and the western region. However, the degree of coordinated development between scientific and technological innovation, economic development and ecological environment construction decreases obviously after the development level is included. Combined with the analysis on the scale of scientific and technological innovation, economic development and ecological environment construction, it can be found that the reason why the degree of coordination and coordinated development of scientific and technological innovation, economic development and ecological environment construction in the eastern region is not ideal lies in the big gap between the level of allocation of scientific and technological resources, the level of economic development and the level of ecological environment construction caused by the rapid development of scientific and technological innovation and economic society and the relatively slow ecological environment governance. The reason for the high degree of coordination and low degree of coordination between scientific and technological innovation, economic development and ecological environment construction in the central and western regions lies in the slow synchronous development of scientific and technological innovation, economic development and ecological environment construction. The reason why the coordination degree and coordinated development degree of scientific and technological innovation, economic development and ecological environment construction in Northeast China are extremely low is that the development degree of scientific and technological innovation and economic development is slower than that of other regions, and the degree of ecological environment construction is better than that of other regions.

\section{AUTHORS' CONTRIBUTIONS} $\mathrm{Wu}$.

This paper is independently completed by Dan

\section{REFERENCES}

[1] Meng Weidong, Wang Qing. An Empirical Analysis on the Factors Influencing the Allocation Efficiency of Scientific and Technological Resources in Regional Innovation System [J]. Statistics and Decision, 2013(4):96-99. (in Chinese)

[2] Dang Yaru, Peng Lina. Evaluation and Analysis on the Development of Science Technology Resource Allocation Efficiency [J]. Science and Technology Management Research, 2012(20): 81-84. (in Chinese)

[3] Wu Chenghe, Zheng Chuiyong. An empirical analysis of the relative effectiveness of the allocation of scientific and technological resources [J]. Science Management Research, 2003, 21(3):93-96. (in Chinese) 
[4] Xu Zhi, Shi Ping. An assessment of the relative efficiency of investment in science \& technology - Positive analysis based on DEA [J]. Studies in Science of Science, 2005, 23(4):481-484. (in Chinese)

[5] Wang Shoubao. Research on Evaluation of Relative Efficiency of Regional S\&T Resources Allocation [J]. Economic Research, 2010, 31(7):48-51. (in Chinese)

[6] Chun-Chu Liu, Chia-Yon Chen.A TwoDimensional Model for Allocating Resources to R\&D Programs[J].Journal of American Academy of Business,2004,5(1/2):459-473.

[7] Zhao Junjie. Using Science and Technology Resource Reasonably to Improve the Productivity $[\mathrm{J}]$. Forum on Science and Technology in China, 2005(6):9-23. (in Chinese)

[8] Liu Lei, Hu Shuhua. Comparative research on R\&D management in China and foreign countries and its enlightenment to the allocation of science and technology resources in China [J]. Research in Science of Science, 2000,18(1): 62-66. (in Chinese)

[9] Evenson. R. E. Patents, R\&D, and invention potential: International evidence $[\mathrm{J}]$. The American Economic Reciew, 1993, 83: 463468.

[10] Yu Liping, Zheng Yanning, Pan Yuntao, Wu Yishan. Research on Index Optimization of Data Envelopment Analysis in Science and Technology Evaluation [J]. Forum on Science and Technology in China, 2008, (4): 105-109. (in Chinese)

[11] Wei Shouhua, Wu Guisheng. Study on the allocation efficiency of regional science and technology resources [J]. Studies in Science of Science, 2005, 23(4): 467-473. (in Chinese)

[12] Wu Fengqing, Li Yuxian, Zhang Xicai. Study on the Coordination of China's Science and Technology and Economy [J]. Statistics and Decision, 2008, (16): 41-42. (in Chinese)

[13] Dai Jinhui. Study on the Coordinated Development of Science, Technology and Economy in Various Regions of China [J]. Economic Research Guide, 2011, (15):138139. (in Chinese)
[14] Liu Manfeng. The harmonious comparison analysis of technological development \& economical development of six provinces in middle China [J]. Science and Technology Management Research, 2010,(1):74-77. (in Chinese)

[15] Wang Yanming, $\mathrm{Xu}$ Qifa. Comparison Analysis on the Coordination Degree between Science \& Technology and Economy in difterent Regions in China [J]. Science and Technology Progress and Policy, 2009, 26(20): 29-31. (in Chinese)

[16] Wu Fengqing, Li Yuxian, Zhang Xicai. Study on the Coordination of China's Science and Technology and Economy [J]. Statistics and Decision, 2008(16):41-42. (in Chinese)

[17] Dong Ye, Annival Amuti. Evaluation of Coordination Degree of Regional Science \& Technology and Economic and Social Development - An Empirical Study Based on Xinjiang [J]. Inquiry into Economic Issues, 2010(12):82-88. (in Chinese)

[18] Dong Huizhong, Zhang Feng, Yin Xiuqing. Dynamic Correlative Analysis between Science and Technology Level and Low Carbon Economy Based on Extension Evaluation $[\mathrm{J}]$. Journal of Finance and Economics Theory, 2015(3):1-8. (in Chinese)

[19] Wang Jieyong, Wu Jianzhai. Analysis of the dynamic coupling processes and trend of regional eco-economic system development in the Yellow River Delta [J]. Acta Ecologica Sinica, 2012, 32(15): 4861-4868. (in Chinese)

[20] He Bing. Comparative Study on the Coordinated Development of "EconomySociety-Ecology" in BRIC Countries [D]. Shenyang: Liaoning University, 2015. (in Chinese)

[21] Wang Lixian. Connotation and Disposition of Eco-Environment Conservation [J]. Resources Science, 2004(S1): 26-33. (in Chinese)

[22] Wang Wei, Zhang Jianye, Qiao Penghua. Research on the coordinated development of regional scientific and technological talents, industrial economy and ecological environment - Based on panel data of 18 larger cities in China $[\mathrm{J}]$. Science and Technology Progress and Policy, 2014,31(7):37-42. (in Chinese) 
[23] Li Guo. Research on the effective support ability of resources and environmental science and technology in the emerging industrialization of Harbin City [D]. Harbin: Harbin Engineering University, 2006. (in Chinese)

[24] Chi Shan, Zhang Hua. Study on the coordinated development of ecological environment and economy in Liaoning coastal economic zone $[\mathrm{J}]$. Ocean Development and Management, 2014(2):93-98. (in Chinese)

[25] Zhang Mingfa, Wang Qiang, Zeng Yue'e. Research on Coordinated Development of Eco-environment and Socio-economy in Xiamen City [J]. Journal of Fujian Normal University (Natural Science Edition), 2015, 31(6):99-108. (in Chinese)

[26] Jiang Yonghong, Liu Dongping. Comprehensive evaluation of the coordinated development of resources, environment and economy in Anhui Province [J]. Agricultural Technology Economy, 2012, (7): 94-102. (in Chinese)

[27] Wei Yiming, Zeng Rong, Fan Ying, Li Zhijie. The coordinated development of population, resources, environment and economy in Beijing $[\mathrm{J}]$. Chinese Management Science, 2000,8:310-307. (in Chinese)

[28] Lu Jun, Yang Juanjuan. Evaluation and Analysis of the Coordinated Development of Economy and Ecological Environment in Baoying County [J]. Northern Environment, 2010,22(3):46-49. (in Chinese)

[29] Grijac, G., Balan, L. L., Manzuc, M. The interdependence between economic growth and environmental protection [J]. METALURGIA

INTERNATIONAL,2009,14(8): 140-142.

[30] Fuentes, Marcelino. Economic growth and biodiversity $[\mathrm{J}]$. BIODIVERSITY AND CONSERVATION, 2011, 20(14): 3453-3458.

[31] Liu Jinsong. The Coordination Analysis of Scientific and Technological Investment, Technological Progress and Economic Growth in Ethnic Regions - An Empirical Analysis Based on Panel Data of Guangxi and Other 4 Ethnic Regions [J]. Science and Technology Progress and Policy, 2009, (23): 65-68. (in Chinese)
[32] Chen Xun, Shi Tao. Study on the evaluation of the impact of scientific and technological progress on the economic and social development of Chongqing $[\mathrm{J}]$. Science and Technology Management Research, 2009,(8):148-150. (in Chinese)

[33] Dong Ye, Annival Amuti. Evaluation of Coordination Degree of Regional Science \& Technology and Economic and Social Development - An Empirical Study Based on Xinjiang [J]. Inquiry into Economic Issues, 2010,(12):82-88. (in Chinese)

[34] Guo Jiangjiang, Qi Wei, Miao Yajun. Evaluation of Coordinated Degree between Science \& Technology and Economic \& Social Development [J]. China Science and Technology Forum, 2012, (5): 123-129. (in Chinese)

[35] Sun Xijie. Analysis on the exponential law of the coordinated growth of science and technology and economy - on the feign of "exponential growth" in the scale of science and technology $[\mathrm{J}]$. Research in Science of Science, 2012, 30(6):813-818. (in Chinese)

[36] Mills, Julianne H.,Waite, Thomas A. Economic prosperity, biodiversity conservation, and the environmental Kuznets curve $[\mathrm{J}]$. ECOLOGICAL ECONOMICS, 2009, 68(7): 2087-2095.

[37] Jiang Xin, Yan Tingwu. An EKC-Based Analysis of Coordinated Economic Development and Environmental Protection in Poverty-Stricken Areas Based: A Case Study of Zhaotong, Yunan Province [J]. Comparative Economic and Social Systems, 2016(3):31-39. (in Chinese)

[38] Sun Qiankun, Li Yuxin, Ren Feng. An Empirical Analysis on the Coordination Degree of Regional Socio-economic and Resource Environmental Development [J]. Statistics and Decision, 2012(17): 84-87. (in Chinese)

[39] Wang Guoyin. The Choice of the Path to Realize the Coordinated Development of Economy and Environment - Research on the Theory and Countermeasures of the Coordinated Development of Economy and Environment in China [J]. Journal of Dialectics of Nature, 2010, 26(4): 83-88. (in Chinese) 
[40] Liu Gang, Shen Lei, Liu Xiaojie, Yu Xiaodong, Li Angda, Zhang Feifei, Zheng Huayu. Harmonious Interactions between Economic Development and Ecological Environment Conservation in Resource-Rich and Economy-Poor Regions: A Case in Yulin City, Shaanxi Province [J]. Resources Science, 2007, 29(4): 18-24. (in Chinese)

[41] Tong Yufen, Liu Chang'an. Evaluation of the Coordination Degree of the Relationship among Beijing's Population, Economy and Environment $[\mathrm{J}]$. Population and Development, 2013, 19(1): 44-51. (in Chinese) 